\title{
Villous Trophoblast Cell Turnover in Placentas From Preterm Pregnancy and Pregnancy Complicated by Intrauterine Growth Restriction (IUGR)
}

\author{
Monika ZADROŻNA, Barbara NOWAK, Antoni MARCINEK, and Joanna DUC
}

Accepted September 15, 2009

\begin{abstract}
ZAdroŻNA M., NOWAK B., MARCinEK A., DuC J. 2010. Villous trophoblast cell turnover in placentas from preterm pregnancy and pregnancy complicated by intrauterine growth restriction (IUGR). Folia biol. (Kraków) 58: 79-83.

Disturbed trophoblast turnover, a key process in placental physiology, may lead to a number of pregnancy-associated pathologies. This study examines PCNA expression and describes and quantifies morphological changes during trophoblast turnover in preterm placentas and term placentas complicated by IUGR. The number of CTF cells increased two-fold in preterm and IUGR placentas. A concurrent and slightly reduced proliferation rate of these cells was also found. The number of STF nuclei of terminal villi was lower by $21 \%$ in IUGR and by $18 \%$ in preterm placentas $(\mathrm{P}>0.05)$. A statistically significant reduction of the number of syncytial knots by $50 \%$ as compared to the control placentas was observed. Correlations between PCNA-reactive CTF nuclei and syncytial knots, PCNA-reactive CTF nuclei and CCO activity, and CCO activity and syncytial knots were found. Moreover, a strong inverse relation was observed between syncytial knots and CTF cells, and CCO activity and CTF cells.

Key words: IUGR placenta, preterm placenta, trophoblast turnover, proliferation, morphometry.

Monika ZADROŻNA, Barbara NOWAK, Joanna DUC, Department of Cytobiology, Collegium Medicum, Jagiellonian University, Medyczna 9, 30-688 Kraków, Poland.

E-mail:mfzadroz@cyf-kr.edu.pl

Antoni MARCINEK, R. J. Czerwiakowski Hospital of Gynecology and Obstetrics, Siemiradz-
\end{abstract} kiego 1, 31-137 Kraków, Poland.

Trophoblast is a cell type specific to the placenta. It covers the surface of placental villi separating maternal and fetal blood circulations. The trophoblast consists of an inner layer of proliferated stem cells called the cytotrophoblast (CTF) and an outer multinucleated layer called the syncytiotrophoblast (STF). The STF layer is in permanent contact with maternal blood. It plays an important role in placental functions such as gas exchange and active transport of substances needed for proper fetus development. Moreover, it also displays endocrine functions. Due to its high degree of differentiation, the syncytiotrophoblast does not display proliferation abilities (BOYD \& HAMILTON 1970; BENIRSCHKE et al. 2006). Thus, the growth and regeneration of the STF during pregnancy depends on the continuous incorporation of villous CTF by fusion into STF. Due to this process, new proteins and mRNA are delivered to the syncytium. Old material is accumulated in structures called syncytial knots. Then, this material is removed to the maternal blood circulation to equilibrate the constant influx of new material through syncytial fusion into STF (HUPPERTZ et al. 2002). Transformation of the trophoblast is strictly correlated with apoptosis. The early stages of apoptosis are correlated with differentiation of CTF and then with its fusion into STF (BLACK et al. 2004). An incorporation of CTF by fusion into STF seems to delay subsequent steps of apoptosis. This results in the removal of total apoptotic nuclei within syncytial knots (HUPPERTZ et al. 1998; MAYHEW et al. 1999). Any aberrations in the function of these processes can result in various pregnancy complications, for example preeclampsia (JOHANSEN et al. 1999; HUPPERTZ 2006). Higher proliferation rate and intensification of apoptosis in the villous trophoblast have been observed in placentas with preeclampsia (ALLAIRE et al. 2000; ISHIHARA et al. 2002). Moreover, intensification of apoptotic processes was found in the placental trophoblast complicated by intrauterine fetus growth restriction (IUGR), (EREL et al. 2001; ISHIHARA et al. 2002; LEVY et al. 2002).

The main goal of this work was the analysis of processes of transformation of the villous tropho- 
blast in human placenta derived from prematurely terminated (PT) and full-term pregnancies complicated by IUGR. Both the IUGR and prematurely terminated pregnancies are important clinical problems of modern perinatology. Both clinical problems are associated with low birth weight, an increase of disease incidence and high perinatal mortality of newborns (KUFEL et al. 2003; REDLINE 2008). The cause of these pregnancy pathologies is still unknown. However, it is already acknowledged that the placenta plays a crucial role in these pathologies (BRODSKY \& CHRISTOU 2004; REDLINE 2008).

\section{Material and Methods}

\section{Collection of samples}

Human placentas were obtained from mothers immediately after spontaneous delivery. Placentas were taken from 6 preterm pregnancies between 34-37 weeks (preterm), 6 from term pregnancies (38-41weeks) complicated by IUGR, and 8 from normal term pregnancies (38-40 weeks). The latter placentas served as control material. IUGR cases were identified by deficient fetal growth on ultrasound scans and the final determinant was an individualized birth weight ratio below the 10th percentile. None of the women had smoking or drinking habits. No significant differences were observed in maternal age. Newborn birth weights and placental weights were measured (Fig. 1). Tissue sections obtained from each placenta were studied by morphological and immunohistochemical methods.

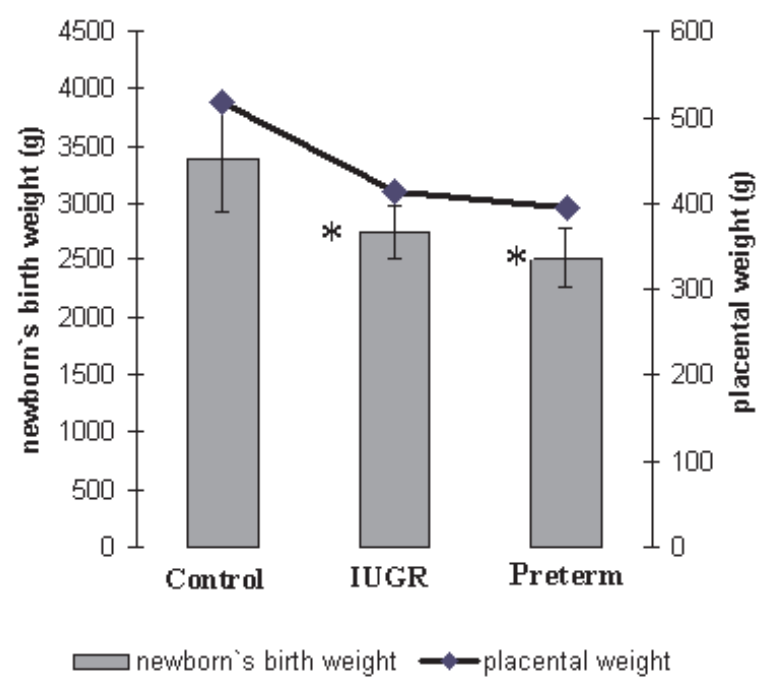

Fig. 1. Mean placental weight (g) and newborn birth weight (g) $\pm \mathrm{SEM}$ in the control, IUGR and preterm groups $* \mathrm{P}<0.05$ compared with control group.

\section{Histological procedure}

The placental tissues obtained were immediately fixed in a neutral phosphate-buffered $4 \%$ formaldehyde solution, dehydrated in a graded series of ethanol and embedded in paraffin. Serial sections of $6 \mathrm{~m}$ were deparaffinized and rehydrated through graded alcohol by standard histological procedures. Then the tissue sections were processed for morphological analysis and immunohistochemical detection of PCNA (proliferating cell nuclear antigen). PCNA functions as a co-factor for DNA polymerase delta in $\mathrm{S}$ phase and also during DNA synthesis associated with DNA damage repair mechanisms (KURKI et al. 1988). The temporal pattern of PCNA expression makes it a useful tool for the study of cell proliferation.

To quantify morphometric analyses of CTF and STF nuclei and the number of syncytial knots, tissue sections were stained with (PAS) and Mayer's hematoxilin. The number of nuclei within CTF and STF of terminal villi was counted under $250 \times$ magnification and was referred to a $0.01 \mathrm{~mm}^{2}$ villous cross section area. A quantification of syncytial knots was conducted under the same microscopic conditions. Only terminal villi (caliber about $60 \mu \mathrm{m}$ and half of the stromal cross section occupied by capillary lumen) were taken into account. The outcomes express the average number of syncytial knots to villous cross section.

\section{Immunohistochemistry}

Deparaffinized and rehydrated sections of $6 \mu \mathrm{m}$ were immersed sequentially in $1 \% \mathrm{H}_{2} \mathrm{O}_{2}$ in methanol for $30 \mathrm{~min}$, blocked with normal serum and incubated at $4^{\circ} \mathrm{C}$ overnight with monoclonal mouse anti-PCNA, clone PC 10 (Novocastra, UK) diluted 1:100 in phosphate-buffered saline (PBS). PBS was used for all subsequent washes and for antiserum dilution. The next day, after several washes, the slides were incubated with a biotinylated secondary antibody (LAB-SA Detection System, ZYMED, US) for $10 \mathrm{~min}$ at room temperature, and streptavidin-peroxidase complex (LAB-SA Detection System, ZYMED, US) for $10 \mathrm{~min}$ at room temperature. The binding of primary antibody was visualized using diaminobenzidine (DAB) for 3-5 min. After washing with distilled water, sections were counterstained with PAS, dehydrated in ethanol and xylene and mounted in the DPX medium (Fluka). Control reactions omitting the primary antibodies were always negative. The mean number of PCNA-immunoreactivity CTF nuclei were calculated in $0,01 \mathrm{~mm}^{2}$ of the terminal villi cross sections area.

Morphometric calculations including numbers of CTF cells, STF nuclei and PCNA-positive nu- 
clei were done with a microcomputer microscope image analyzer combined with the programme Cell-D.

\section{Statistical methods}

Means and standard errors of means (SEM) were calculated for each group. Comparisons between groups were carried out using Kruskal-Wallis ANOVAs and post hoc by Dunn's multiple comparison tests. For all normally distributed vari- ables, Pearson's correlation coefficients were calculated. Statistical significance was established at $\mathrm{P}<0.05$.

\section{Results and Discussion}

In the present study we found a two-fold increase of the number of CTF cells in preterm and IUGR placentas (Fig. 2) and a slightly reduced proliferation rate of these cells (Fig. 3); a statistically sig-

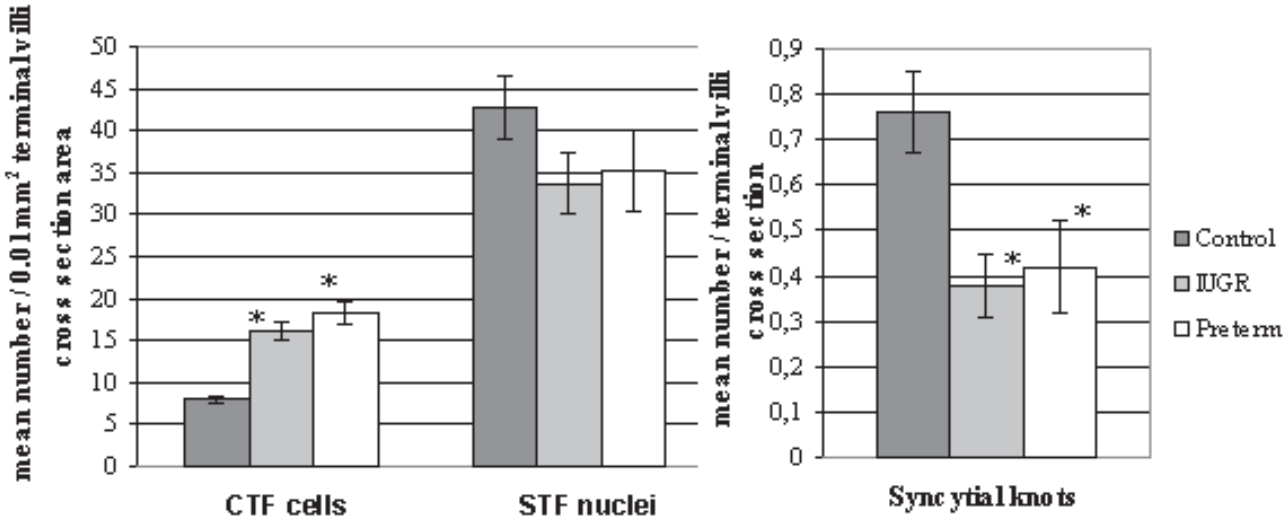

Fig. 2. Mean number and \pm SEM of CTF cells and STF nuclei (per $0.01 \mathrm{~mm}^{2}$ of terminal villi cross section area) and syncytial knots (per terminal villi cross section) in the control, IUGR and preterm placental trophoblast. ${ }^{*} \mathrm{P}<0.01$ compared with control group.
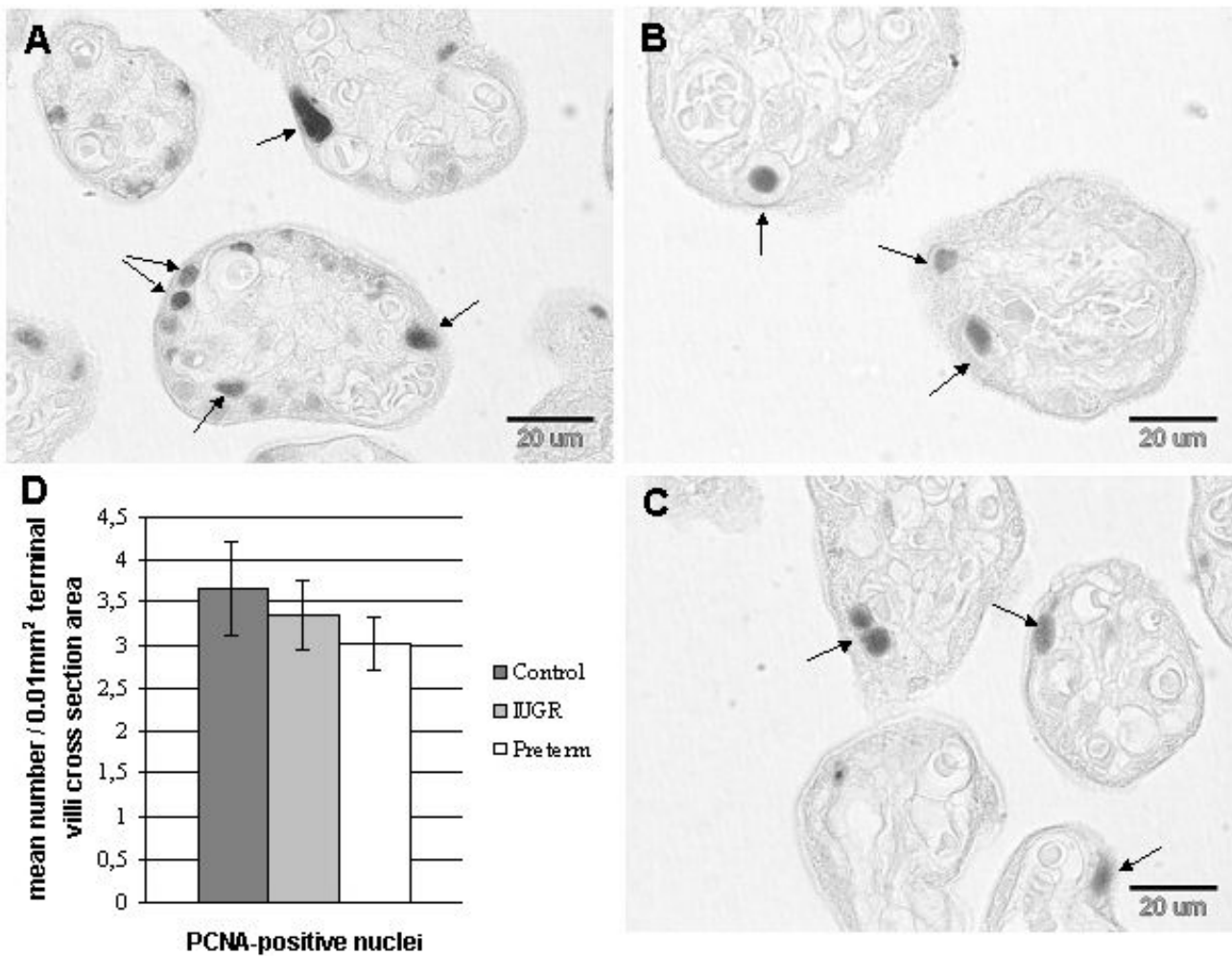

Fig. 3. Immunohistochemical staining of PCNA to identify proliferating CTF cells (arrows) in the control (A), IUGR (B) and Preterm (C) placental terminal villi. D. Results are expressed as the mean \pm SEM number of PCNA-positive nuclei/0.01 mm ${ }^{2}$ terminal villi cross section area. $\mathrm{P}>0.05$ 
nificant reduction of the number of syncytial knots by $50 \%$ as compared to the control placentas (Fig. 2) and slightly reduced but insignificant number of STF nuclei of terminal villi. We also observed a decrease of the mean birth weight of the newborns from preterm and IUGR pregnancies which correlated with the mean weight of the placentas (Fig. 1).

Proper growth and functionality of the human placenta during pregnancy plays the most important role in the development of the fetus. Numerous studies have revealed placental dysfunctions as the main cause of various pregnancy complications (BRODSKY \& CHRISTOU 2004; FOX 1997; MEHTA et al. 2006). A low birth weight of newborns is one of the symptoms of pregnancies terminated before the delivery term and complicated with IUGR (ZAW et al. 2003; KAMATH et al. 2006). In this study, the mean birth weights of newborns from preterm and IUGR pregnancies were lower compared to the control newborns (Fig. 1) and correlated with the mean placenta weight $(\mathrm{r}=0.8085$, $\mathrm{P}<0.001$ ). This study not only confirms the relationship observed by many researches (JACKSON et al. 1995; DAAYANA et al. 2004) but also underlines the role of the placenta in these pathologies.

The villous trophoblast plays a main role in the functionality of the placenta. It is subject to the continuous transformation, differentiation and fusion of CTF into STF cells. The first stages of trophoblast transformation include proliferation of CTF cells followed by their differentiation. This process results in the fusion of CFT cells into the syncytiotrophoblast. In initially distinct and continuous cytotrophoblast layers, the number of cells gradually decreases in normal pregnancy, so that only a small number of CTF cells remains in the placenta of a full-term pregnancy (BENIRSCHKE et al. 2006; FoX 1997). However, the two-fold increase of CTF cells in terminal villi from preterm and IUGR placentas was observed in the analyzed material as compared to control group $(\mathrm{P}<0.01$; Fig. 2). A concurrent and slightly reduced proliferation rate of these cells was also found $(\mathrm{P}>0.05$; Fig. 3). Taking into consideration the decrease in the number of proliferated CTF cells during pregnancy (ISHIHARA et al. 2000), it should be expected that most of these cells are in preterm placentas. However, in the analyzed preterm placentas of CTF nuclei with PCNA reactivity, the number of cells was lower by $13 \%$ as compared to control placentas (Fig. 3). This observation can provide information about cell proliferation disorders in these placentas. Reduced proliferation activity of CTF cells in placentas complicated by IUGR was also detected by MACAR et al. (1995), CHEN et al. (2002), and GUREL et al. (2003), using different cell proliferation markers. However, in- creased cell proliferation was observed in preeclampsia placentas (LEUNG et al. 2001).

The reduced proliferation rate and accumulation of CTF cells in the trophoblast of placental terminal villi of preterm and IUGR indicates the reduction of supplying processes of the syncytiotrophoblast layer in new cellular material. This can result in improper growth and functionality of the layer and acceleration of syncytial apoptosis (HUPPERTZ et al. 1999), contributing to placental transport malfunction. The analysis of STF nuclei and syncytial knots also confirms this phenomenon. The average number of STF nuclei per cross-section $\left(0.01 \mathrm{~mm}^{2}\right)$ of terminal villi was lower by $\sim 21 \%$ in IUGR placentas and $18 \%$ in preterm placentas. However, these data were not statistically significant (Fig. 2). However, a statistically significant reduction of the number of syncytial knots by $50 \%$ as compared to the control placentas was observed. This reduction runs parallel with lower numbers of STF nuclei in preterm and IUGR placentas. On average, one terminal villous of control placental crosssection corresponds to 0.76 syncytial knots. This ratio was 0.42 and 0.38 for IUGR and preterm placentas, respectively $(\mathrm{P}<0.01$; Fig. 2$)$. The correlation between the number of syncytial knots and the CTF cells $(r=-0.7327, P=0.001)$ and between the number of CTF nuclei with PCNA-reactivity and syncytial knots $(r=0.4929, \mathrm{P}=0.04)$ shows the relationship between the proper course of the early stages in transformation of villous trophoblast and the terminal phase of this process.

Because fusion and further syncytial apoptosis is an energy-dependant process, HUPPERTZ et al. (2006) stated that under moderate hypoxia conditions and during disturbed transport of protein and mRNA to the STF, no stages of apoptosis or removal of apoptotic nuclei within the syncytial knots occur. As a consequence of this process, the old and partially apoptotic syncytial nuclei are removed by necrosis or aponecrosis (FORMIGLI et al. 2000). This phenomenon results in local tissue damage (HUPPERTZ \& KINGDOM 2004). Many studies (HEAZELL et al. 2008; BENIRSCHKE et al. 2006) draw attention to the influence of hypoxia on the inhibition of CTF cell differentiation and aggregation. The activity of the main oxidative enzyme, cytochrome c oxidase (CCO), was histochemically examined in the analyzed group of placentas (described in a previous paper; ZADROŻNA et al. 2009). The activity of the CCO was lower by $11 \%$ and $28 \%$ in IUGR and preterm placentas, respectively, as compared to control placentas. Moreover, the CCO activity was significantly correlated with the number of CTF cells $(\mathrm{r}=-0.5938, \mathrm{P}=0.001)$, PCNA-reactive CTF nuclei $(\mathrm{r}=0.4931, \mathrm{P}=0.04)$, and syncytial knots $(\mathrm{r}=$ $0.5799, \mathrm{P}=0.001)$. 
In conclusion, a different model of transformation of placental villous trophoblast in IUGR and preterm was described based on the obtained results. This model undoubtedly could play a role in the IUGR pathomechanism and premature birth. The observed changes were more intense in preterm placentas, which may result in pregnancy ending before term.

\section{References}

Allaire A. D., Ballenger K. A., Wells S. R., MCMaHON M. J., LESSEY B. A. 2000. Placental apoptosis in preeclampsia. Obstet. Gynecol. 96: 271-276.

BenirschKe K., Kaufmann P., BaERgen R. 2006. Pathology of the Human Placenta. $5^{\text {th }}$ ed. Springer, New York.

Black S., Kadyrov M., KaUfmann P., UgEle B., EMANS N., HuPPERTZ B. 2004. Syncytial fusion of human trophoblast depends on caspase 8. Cell Death and Differentiation 11: $90-98$

Boyd J. D., Hamilton W. J. 1970. The Human Placenta. Cambridge, W. Heffer \& Sons.

BRODSKY D., CHRISTOU H. 2004. Current concepts in intrauterine growth restriction. J. Intensive Care Medicine 19: 307-319.

Chen C. P., BAJORIA R., APLin J. D. 2002. Decreased vascularization and cell proliferation in placentas of intrauterine growth restricted fetuses with abnormal umbilical artery flow velocity waveforms. Am. J. Obstet. Gynecol. 187: 764-769.

DAAYANA S., BAKER P., CROCKER I. 2004. An image analysis technique for the investigation of variations in placental morphology in pregnancies complicated by preeclampsia with and without intrauterine growth restriction. J. Soc. Gynecol. Investig. 11: 545-562.

Erel C. T., Dane B., Calay Z., Kaleli S., Aydinli K. 2001. Apoptosis in the placenta of pregnancies complicated with IUGR. Int. J. Gynecol. Obstet. 73: 229-35.

Formigli L., PAPUCCI L., TANI A., SCHIAVONE N., TEMPESTINI A., ORlandini G. E., CAPACCIOli S. ORLANDINI S. Z. 2000. Aponecrosis: morphological and biochemical exploration of a syncretic proces sof cell Heath sparing apoptosis and necrosis. J. Cell Physiol. 182: 41-49.

Fox H. 1997. Pathology of the Placenta. W. B. Sanders Company Limited.

Gurel D., Ozer E., Altunyurt S., Guclu S., Demir N. 2003. Expression of IGR-IR and VEGF and trophoblastic proliferative activity in placentas from pregnancies complicated by IUGR. Pathol. Res. Pract. 199: 803-809.

Heazell A. E. P., LACEy H. A., JoneS C. J. P., HupPertz B., BAKER P. N., CROCKER I. P. 2008. Effects of oxygen on cell turnover and expression of regulators of apoptosis in human placental trophoblast. Placenta 29: 175-186.

Huppertz B., Frank H. G., Kingdom J. C., Reister F., KAUFMANN P. 1998. Villous cytotrophoblast regulation of the syncytial apoptotic cascade in the human placenta. Histochem. Cell Biol. 110: 495-508.

Huppertz B., Frank H. G., Reister F., Kingdom J. C., KorR H., KaUfmanN P. 1999. Apoptosis cascade progresses during turnover of human trophoblast: analysis of villous cytotrophoblast and syncytial fragments in vitro. Lab. Invest. 79: 1687-702.

Huppertz B., Kadyrov M., Kingdom J. C. 2006. Apoptosis and its role in the trophoblast. Am. J. Obstet. Gynecol. 195: 29-39.
Huppertz B., KaufmanN P., Kingdom J. C. 2002. Trophoblast turnover in health and disease. Fetal Maternal Med. Rev. 13: 103-18.

Huppertz B., Kingdom J. C. 2004. Apoptosis in the trophoblast-role of apoptosis in placental morphogenesis. J. Soc. Gynecol. Investig. 11: 353-62.

ISHIHARA N., MATSUO H., MuRAKOSHI H., LAOAG-FERnANDEZ J., SAMOTO T., MARUO T. 2000. Changes in proliferative potential, apoptosis and Bcl-2 protein expression in cytotrophoblast and syncytiotrophoblast in human placenta over the course of pregnancy. Endocrine J. 47: 317-327.

ISHIHARA N., MATSUO H., Murakoshi H., LAOAG-FERnANDEZ J., SAMOTO T., MARUO T. 2002. Increased apoptosis in the syncytiotrophoblast in human term placentas complicated by either preeclampsia or intrauterine growth retardation. Am. J. Obstet . Gynecol. 186: 158-166.

JACKSON M. R., WAlsh A. J., MORROW R. J. Mullen J. B., LyE S. J., RiTCHIE J. W. 1995. Reduced placental villous tree elaboration in small-for-gestational-age pregnancies: relationship with umbilical artery Doppler waveforms. Am. J. Obstet. Gynecol. 172: 518-525.

JOHANSEN M., REDMAN C. W., WILKINS T., SARGENT I. L. 1999. Trophoblast deportation in human pregnancy-its relevance for pre-eclampsia. Placenta 20: 531-539.

KAMATH U., RAO G., KaMATH S. U., RAI L. 2006. Maternal and fetal indicators of oxidative stress during intrauterine growth retardation (IUGR). Indian J. Clinical Biochem. 21: 111-115.

KufEL K., RudzińsKa I. M., KoRnACKA K. M. 2003. Prematurity and intrauterine growth retardation at birth - comparison of morbidity. Arch. of Perinatal Medicine 9: 28-30.

KurKi P., OGATA K., TAN E. M. 1988. Monoclonalantibodies to proliferating cell nuclear antigen (PCNA) cyclin as probes for proliferating cells by immunofluorescence microscopy and flow-cytometry. J. Immunol. Methods 109: 49-59.

Leung D. N., Smith S. C., To K. F., SAhota D. S., BAKer P. N. 2001. Increased placental apoptosis in pregnancies complicated by preeclampsia. Am. J. Obstet. Gynecol. 184: 1249-50.

LeVy R., SMith S. D., Yusuf K., Huettner P. C., KRAus F. T., SADOVSKY Y., NELSON D. M. 2002. Trophoblast apoptosis from pregnancies complicated by fetal growth restriction is associated with enhanced p53 expression. Am. J. Obstet. Gynecol. 186: 1056-61.

MacarA L., Kingdom J. C., Kohnen G., Bowman A. W., GREER I. A., KAUFMANN P. 1995. Elaboration of stem villous vessels in growth restricted pregnancies with abnormal umbilical artery Doppler waveforms. Br. J. Obstet. Gynecol. 102: $807-12$.

MAYHEW T. M., LEACH L., MCGEE R., WAN ISMAIL W., MYKLEBUST R., LAMMIMAN M. J. 1999. Proliferation, differentiation and apoptosis in villous trophoblast at 13-41 weeks of gestation (including observations on annulate lamellae and nuclear pore complexes). Placenta 20: 407-422.

Mehta R., Nanjundaswamy S., Shen-SchwarZ S., Petrova A. 2006. Neonatal morbidity and placental pathology. Indian J. Pediatrics 73: 25-28.

REDLINE R. W. 2008. Placental pathology: a systematic approach with clinical correlations. Placenta 29, Suppl. A, Trophoblast Research 22: 86-91.

ZADROŻNA M., GAWLIK M., NOWAK B., MARCINEK A., MrOWIEC H., WALAS S., WIETECHA-POSŁUSZNY R., ZAGRODZKI P. 2009. Antioxidants activities and concentration of selenium, zinc and copper in preterm and IUGR human placentas. J. Trace Elem. Med. Biol. 23: 144-148.

ZAW W., GAGNON O., DASILVA O. 2003. The risks of adverse neonatal outcome among preterm small for gestational age infants according to neonatal versus fetal growth standards. Pediatrics 111: 1273-1277. 